\title{
Quantitative and qualitative indicators of safe (pseudo-safe) state of territory's economy
}

\author{
LiudmilaSamoilova*
}

Saint Petersburg Institute (branch) of the All-Russian State University of Justice, 19 A, 10-ya Liniya St., 199178 Saint-Petersburg, Russia

\begin{abstract}
Human capital is the foundation of economic development at the territories, which indicates that its complex judgment is of priority. However, parameters that distort socio-economic reality will give a wrong idea of whether the territory's economy is protected against threats; therefore, finding criteria to distinguish safe, conditionally safe, pseudosafe and danger states of the economy take on special significance. In view of this, development of the system of indicators to estimate human capital has become vital, which has predetermined the purpose of the study implemented using the following methods: statistical analysis and qualitative assessment of systems. The set of the coefficients focuses on better objectivity of the study of human capital in terms of the influence it has on safety of the economy of the territory, since it considers the rate of changes in basic quantitative and qualitative indicators disclosing, on the one hand, availability of labor resources, on the other hand, satisfaction of the households' needs.
\end{abstract}

\section{Introduction}

The category of safety is multifaceted and extends the influence to all life spheres, including economy, by involving macro- and micro structural units; and since these are closely interrelated and interdependent, the state as an actor provides security and satisfies needs of the society in general, and individuals in particular However, needs of diverse economic entities varies, and sometimes, even incompatible due to the contradiction between public and private goals, therefore, to create safe environments, the balance is required. At the same time, when prioritizing, it is typical to acknowledge the supremacy of national interests, and preference is given to elimination of the obstacles that make impossible to solve public problems while disregarding individual needs. Such asymmetry causes pathological states of the territory's economy such as conditionally safe, pseudosafe, and dangerous. Long-term neglecting the interests of households, as a rule, escalates social tension and gradual negative change in macroeconomic indicators, which, in general, is followed by crisis processes in national economies. In that respect, attention should be paid to human potential of a territory, with continuous monitoring its quantitative and qualitative characteristics, while construction of the system of coefficients, which describe the dependence of the territorial and economic complex from human resources and show

${ }^{*}$ Corresponding author: samoylovalk@mail.ru 
the standard and quality of living of the population, and defining their "thresholds" takes on special significance in terms of identifying borderline states of local economy.

\section{Problem Statement and Purpose of Research}

Human capital is the foundation of economic self-reliance of legal entities at different levels because any individual has a dual role in the functioning of national economy. First, it represents a basic economic resource, i.e. labor; second, its ideas serve as a basis for providing other recourse, i.e., technologies. Both are necessary to implement each phase of the replenishment cycle in which economic benefits are generated, used both for public, and for private purposes. Second, physiological and other personal needs form the reason motivating entrepreneurial activity, while for competent authorities, satisfaction of the same serve a measure of maturity of the social targets. Therefore, qualitative and quantitative changes in human potential, both positive and negative, can determine the degree of protection of interests and priorities of all groups of economic subjects. In turn, disregarding long-term negative trend in the life spheres of households will be conducive to growing insecurity not only of the households, but also of the society, and the state as a whole. Mostly, such misjudgment is due not to intent, but to non-obvious regress, since in theory, the most typical macro- and microeconomic indicators are within normal limits. Such neglected points incite the development of not only safe or dangerous states of the national economy, which are in diametrical opposition to each other, but also the boundary ones, i.e. conditionally safe and pseudo-safe states.

Great body of research in economic science is devoted to safety and danger. The first concept is described by basic and accessory parameters, which testify to stability of all spheres of activity of the territory, and of their capability to confront the threats. The other one is characterized by rapid proliferation of destructive phenomena, which consists in successive capture, firstly, of "weak" economic entities, but later leading to systematic destabilization of the national economy. Macro- and micro-indicators have negative deviation from the "thresholds" values. Borderline states have not been adequately reflected in scientific research results; only some publications touch upon pseudo-safety [1,2]. When disclosing these terms, it is worth mentioning that conditional safety is accompanied by invariability of basic macro-indicators, while auxiliary micro-criteria show regular negative and positive variations. Such changes speak for instability. Pseudo-safety is described by "false" appearance of well-being: basic indicators of the national economy given in absolute values are positive, but medium-term relative and rate-based performances reflecting the flow of a number of processes that involve various groups of economic entities, are negative; and if this tendency persists, steady foci of crisis i.e. danger, are emerging. In order to prevent the above negative states, comprehensive research of socioeconomic macro- and micro-regularities take on particular significance. Estimation of human capital is the priority, since it influences well-being of both public and private structures.

Therefore, the purpose of this research has been reduced to the development of the system of indicators, combining multidirectional vectors of estimation of human potential, which should be used to assess the degree of protection of the territory's economy against negative activities. 


\section{Methods of Research}

In the research process, methods of statistical analysis, i.e. relative statistical values, time series; and methods of qualitative assessment of system such as ranking and classification have been employed.

The system of indicators, which describes human potential in terms of quantity and quality, is based on relative statistical values, rate-based coefficients, since absolute parameters are not unconditionally reliable. For example, per capita income of the population estimated in ruble equivalent, might increase from year to year; at the same time, this is not an indication of increase of personal welfare; therefore, the individuals' real income should be estimated, taking into consideration purchasing power of the lawful currency. Using relative and rate-based performances in the context of the influence human capital exerted on the state transition of the territory's economy is justified, since they let determine whether positive or negative trends prevail in human resources management.

Calculation of the set of criteria shown in Fig. 1 and comparison of the same with the "threshold" values made it possible to rank every constituent entity of the Russian Federation, of the one hand, according to the quantitative and qualitative supply of regional economy with labor force, on the other hand, according to the satisfaction of individuals' needs for tangible and intangible goods. Results of the ranking have formed the basis of classification of the regions according to the above aspects.

\section{Results and Discussion}

In terms of the territory's economy safety, human capital should be treated from two perspectives: first, as an element involved in the protection of interests of other micro- and macro-entities; second, as an independent asset to be protected, with the aggregate of needs to be necessarily met, since this determines well-being of the society and state as a whole. Therefore, its assessment should be based on the performances both reflecting the state of labor resources in the region, and characterizing satisfaction of individual needs for tangible and intangible goods (Fig. 1). 


\begin{tabular}{|c|c|}
\hline \multirow{2}{*}{\multicolumn{2}{|c|}{$\sqrt{\begin{array}{c}\text { System of indicators to estimate human capital from the perspective of its } \\
\text { involvement in the territory's economy security }\end{array}}$}} \\
\hline & \\
\hline as economic resource & as an asset to be protected \\
\hline 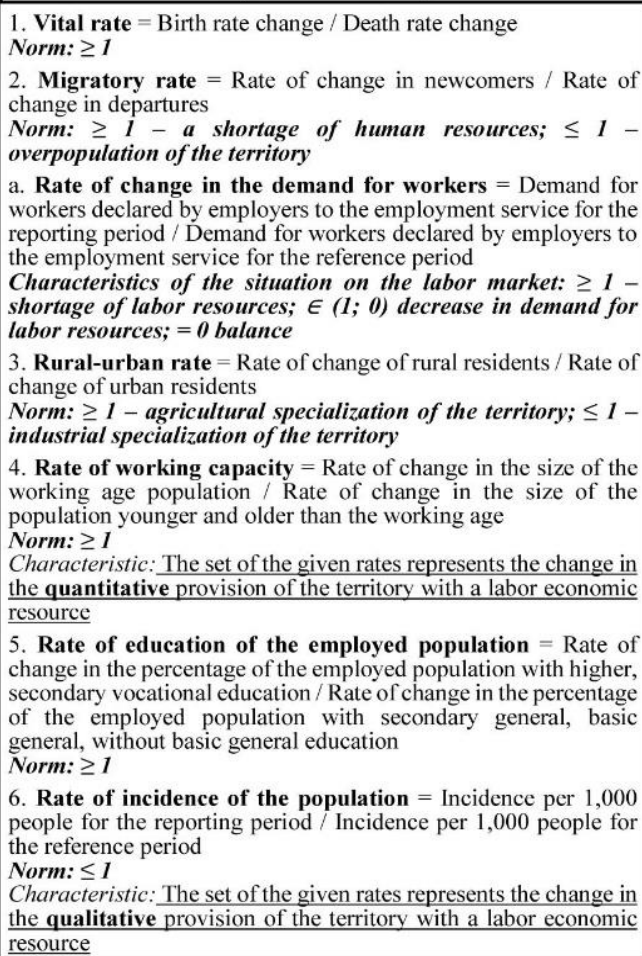 & $\begin{array}{l}\text { 1. Rate of household income and expenditure }=\text { Rate } \\
\text { of change in household income / Rate of change in } \\
\text { household expenditure } \\
\text { Norm: } \geq 1 \\
2 \text {. Ratio of the rate of change in the household income } \\
\text { in percent and the consumer price index = Rate of } \\
\text { change in the household income in percent / Consumer } \\
\text { price index } \\
\text { Norm: } \geq 1 \\
3 \text {. Rate of the debt burden per inhabitant of the } \\
\text { territory = Debt to credit institutions per one resident of } \\
\text { the territory for the reporting period / Debt to credit } \\
\text { institutions per one resident of the territory for the } \\
\text { reference period } \\
\text { Norm: } \leq 1 \\
4 \text {. Rate of abortions per } 100 \text { births }=\text { The number of } \\
\text { abortions per 100 births during the reporting period / The } \\
\text { number of abortions per } 100 \text { births during the reference } \\
\text { period } \\
\text { Norm: } \leq 1 \\
\text { Characteristic: The set of the given rates represents the } \\
\text { change in the population well-being } \\
5 \text {. Rate of accessibility of preschool educational } \\
\text { organizations }=\text { Rate of change in preschool educational } \\
\text { organizations / Rate of change in the number of pupils in } \\
\text { preschool educational organizations } \\
\text { Norm: } \geq 1 \\
6 \text {. Rate of school accessibility = Rate of change in the } \\
\text { number of schools / Rate of the number of students in } \\
\text { schools } \\
\text { Norm: } \geq 1 \\
\text { 7. Hospital availability rate }=\text { Rate of change in hospital } \\
\text { beds / Rate of change in population } \\
\text { Norm: } \geq 1 \\
\text { Characteristic: The set of the given rates represents the } \\
\text { change in the comfort of the territory for living }\end{array}$ \\
\hline
\end{tabular}

Fig. 1 The system of indicating markers characterizing quantitative and qualitative changes of the territory's human capital.

In scientific papers, labor force is estimated in terms of quantity and quality. Some authors put a focus on the parameters of quantitative labor security $[3,4,5]$, while some others give priority to qualitative criteria such as education, health, and age $[6,7,8,9]$.

Identification of satisfaction of an individual's needs is based on different approaches: scientists focus on social inequality [10], financial well-being [11], social guarantees [12].

However, despite numerous vectors applied to assess human potential, it has not been comprehensively studied as a structural element of the state economic security system; in this respect, the opinion provided in this paper, which includes the appreciation, on the one hand, of whether labor resources are adequate for the territorial economic entity to operate, on the other hand, of well-being of the population, is aimed at the elimination of this deficiency. In other words, human capital is treated both as a "basis" involved in the supporting of economic self-reliance of economic entities and the state, and as an asset to be protected on equal terms with the state.

\section{Conclusions}

Summary estimate of the above criteria is shown in Fig. 2. The data is estimated for 83 constituent entities of the Federation (with the exception of the Republic of Crimea and Sevastopol) for the period from 2014 to 2018. In order to represent the obtained digital material compactly, the following scores were ascribed to the performances: "one" for 
normal coefficients, "zero" for those deviating from the norm. Total score for each indicator for five years has been calculated; if the overall score equals to five, the region can be classified as a leader; in case of zero, the region can be treated as an outsider. Intermediate result from one to four indicates unsteady state, i.e. positive course of socioeconomic processes is followed by negative one, and vice versa.

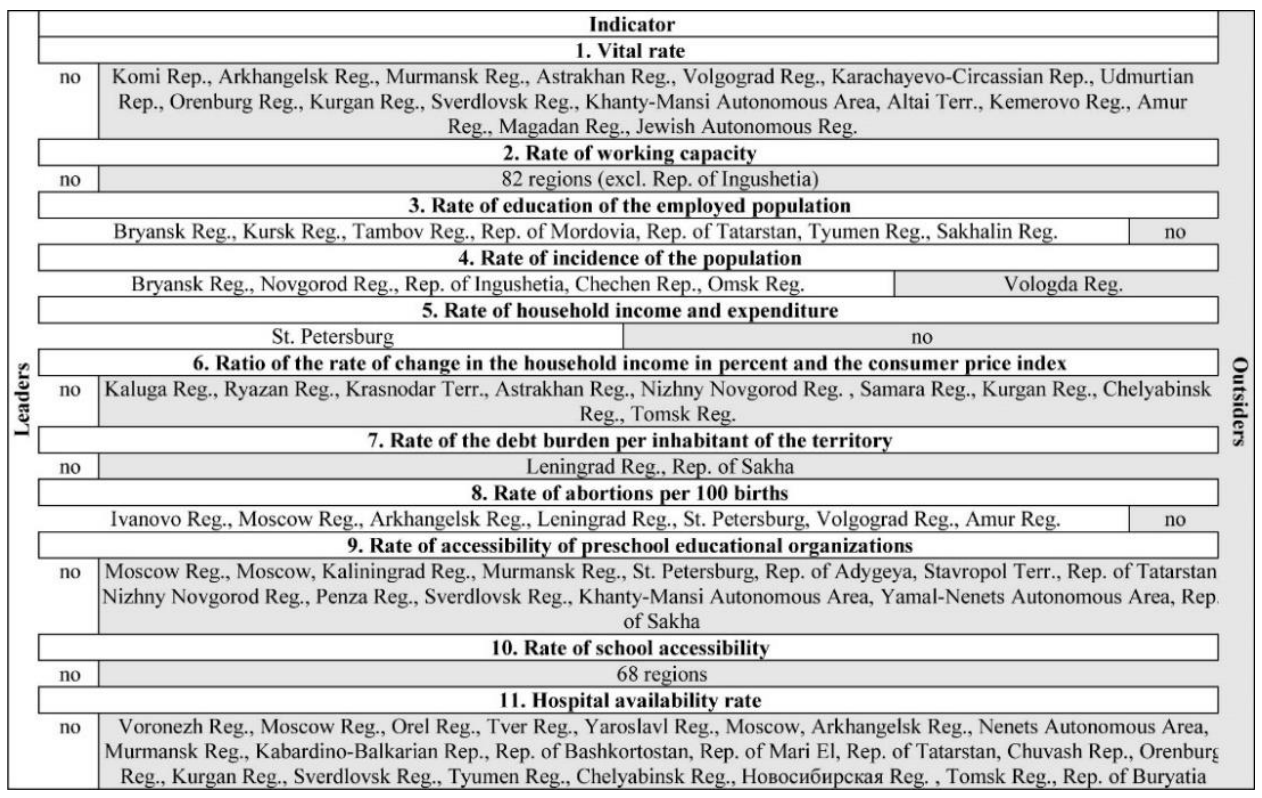

Fig. 2. The list of leaders and outsiders according to indicating markers that describe change in human capital.

Testing of the developed system of coefficients has demonstrated extremely troubled areas relating to human potential, including quantitative inappropriateness of labor resources, low standard and quality of living of the population. In addition, the calculations have formed a basis for the opinion on sufficiency of labor resources in the Russian regions, and on well-being of the citizens.

In general, the author's approach to the estimate of human capital of the territory in terms of economic safety reveals a number of special features:

- it is characterized by systematic nature reflected in multifaceted study of human potential, both as the main economic resource of a territory, and as an asset to be protected, meeting the needs of which is the priority and included in the list of functions and problems of public territorial entities;

- it is based on the use of relative and rate-based performances, which allows for identifying the actual state of the households in terms of financial and social well-being, revealing interconnections and interdependencies in the course of demographic and socioeconomic processes they are involved in, as well as identifying the most likely crisis "areas";

- it includes not only the indicators, but also their standard value. Verification of conformity or deviation of the calculated indicating markers from the threshold values reflects the protection of the territory's economy against negative activities, and therefore, it is possible to estimate the state of economy formed by a given moment: safe, conditionally safe, pseudo-safe, or dangerous. 


\section{Acknowledgements}

The reported study was funded by RFBR, project number 20-010-00387 A.

\section{References}

1. A.A. Kuklin, I. V. Korobkov, Economy of Region, 14 (4), 1145 (2018)

2. A.A. Kuklin, N. V. Krivenko, L. A. Kriventsova, International Research Journal, 89 (11), 166 (2019)

3. R.V. Fattakhov, M.M. Nizamutdinov, V.V. Oreshnikov,Economy of Region, 15 (2), 436 (2019)

4. O.E. Podverbnykh, S.M. Samokhvalova, Ekonomikaregiona, Economy of Region,15 (4), 1141 (2019)

5. AS.V. Doroshenko, A.G. Shelomentsev,Economy of Region, 15 (4), 1115 (2019)

6. I.A. Korshunov, O.S. Gaponova, N.S. Gaponova, Economy of Region, 15(1), 107 (2019)

7. A. Guliyeva, N. Chunikhina, A. Guliyeva, A. Abdulova, Terra Economicus,17(1), 64(2019)

8. A.V. Karavay, Journal of Institutional Studies, 10 (2), 59 (2018)

9. A.E. Fyodorova, V.S. Katashinskikh, Z. Dvorakova, Economy of Region, 12 (3), 802814 (2016)

10. M.Yu. Malkina, Terra Economicus, 15 (4), 46 (2017)

11. N.V. Latova, Journal of Institutional Studies, 10 (2), 44 (2018)

12. R.V. Gubarev, E.I. Dzyuba, O.M. Kulikova, F.S. Fayzullin, Journal of Institutional Studies, 11 (2), 146 (2019) 